Vol. 11 (2): 331-336 (2021)

\title{
ON THE CHARACTERISTICS OF ALKALI- AND ACID- ACTIVATED BENTONITE OF KOSOVO TO BE USED FOR OIL RECYCLING
}

\author{
Valdet Teneqja $^{1}$, Arjan Korpa ${ }^{2 *}$, Spiro Drushku ${ }^{3}$, Arianit Reka ${ }^{4}$, Enkeleida Skënduli $^{2}$ \\ ${ }^{1}$ Laboratory "Ex Fis Labs", Pristina, Kosovo; \\ 2*Department of Chemistry, Faculty of Natural Sciences, University of Tirana, Albania; \\ ${ }^{3}$ Department of Industrial Chemistry, Faculty of Natural Sciences, University of Tirana, Albania; \\ ${ }^{4}$ Department of Chemistry, Faculty of Natural Sciences and Mathematics, University of Tetovo, North Macedonia; \\ *Corresponding Author Arjan Korpa, e-mail: arjan.korpa@fshn.edu.al;
}

Received February 2021; Accepted March 2021; Published April 2021;

DOI: https://doi.org/10.31407/ijees11.219

\begin{abstract}
Clay minerals are natural products with very high absorbent, ion-exchange and catalytic properties; chemical nature and pore structure have an important impact on these properties. In this paper, it is proposed to modify the Bentonite clay of Kosovo (Goshica region) by acid and alkali activation to be used for oil recycling. Acid and alkali activation was performed in ratios $(10,30$ and 50\%) in order to see the effect of acid and alkali treatment on the properties of Goshica Bentonite. The samples were characterized using X-ray powder diffraction (XRD), Fourier transform infrared (FTIR), structural and chemical analysis. Physio-chemical analysis was performed to find out the best activation treatment in order to increase the bentonite's adsorption and ions exchange capacity. Significant changes were observed in the original pore structure. All the conclusions drawn correlate well with the amount of activator used. This study will provide valuable data on the effect of acid and alkali activated bentonite for the treatment and recyclability of UMO, which is essential for local industry.
\end{abstract}

Keywords: Bentonite characteristics, alkali and acid activation, Kosovo bentonite, used motor oil (UMO). 